\title{
Implicit sequence learning is preserved in dyslexic children
}

\author{
Filomena Inácio $^{1}$ (D) Luís Faísca $^{1}$ • \\ Christian Forkstam ${ }^{1}$ - Susana Araújo ${ }^{2}$. \\ Inês Bramão ${ }^{1,3}$ - Alexandra Reis ${ }^{1}$ • \\ Karl Magnus Petersson ${ }^{1,4}$
}

Received: 14 July 2017 / Accepted: 19 March 2018 / Published online: 3 April 2018

(C) The International Dyslexia Association 2018

\begin{abstract}
This study investigates the implicit sequence learning abilities of dyslexic children using an artificial grammar learning task with an extended exposure period. Twenty children with developmental dyslexia participated in the study and were matched with two control groups - one matched for age and other for reading skills. During 3 days, all participants performed an acquisition task, where they were exposed to colored geometrical forms sequences with an underlying grammatical structure. On the last day, after the acquisition task, participants were tested in a grammaticality classification task. Implicit sequence learning was present in dyslexic children, as well as in both control groups, and no differences between groups were observed. These results suggest that implicit learning deficits per se cannot explain the characteristic reading difficulties of the dyslexics.
\end{abstract}

Keywords Artificial grammar learning $\cdot$ Children · Dyslexia $\cdot$ Implicit learning $\cdot$ Reading acquisition

Filomena Inácio

fcinacio@ualg.pt

1 Cognitive Neuroscience Research Group, Center for Biomedical Research (CBMR), University of Algarve, Faro, Portugal

2 Faculdade de Psicologia and Center for Psychological Research, Universidade de Lisboa, Lisbon, Portugal

3 Department of Psychology, Lund University, Lund, Sweden

4 Max Planck Institute for Psycholinguistics, Nijmegen, The Netherlands 


\section{Introduction}

Developmental dyslexia (henceforth, dyslexia) is the most common learning disorder, and it is characterized by severe and persistent difficulties in learning how to read, despite normal intelligence, adequate cognitive abilities, and appropriate instruction (Lyon, Shaywitz, \& Shaywitz, 2003; Tunmer \& Greaney, 2011; Vellutino, Fletcher, Snowling, \& Scanlon, 2004). A vast number of studies have identified a phonological processing difficulty as a core feature of dyslexia, specifically, underspecified, or/and less accessible phonetic representations in these readers (e.g., Boets et al., 2013; Ramus et al., 2003). Indeed, individuals with dyslexia have been shown to perform below average on a range of tasks that require phonological processing skills (e.g., phonological awareness, phonological decoding, rapid automatized naming, and verbal short-term memory) (Ramus et al., 2003; Shaywitz, 2003; Tijms, 2004; Wagner, Torgesen, \& Rashotte, 1994). In addition, dyslexia disorder has been linked to nonlinguistic processing deficits, including visual and auditory processing (Sela, 2014), visual spatial attention (Franceschini, Gori, Ruffino, Pedrolli, \& Facoetti, 2012), and, discussed more recently, to implicit learning (for a review, see Folia et al., 2008; Lum, Ullman, \& ContiRamsden, 2013; Schmalz, Altoè, \& Mulatti, 2017; van Witteloostuijn, Boersma, Wijnen, \& Rispens, 2017). The term implicit learning was introduced by Reber (1967) and refers to a type of unintentional learning that results from constant exposure to environmental regularities, without awareness of what has been learned. This process is not voluntary mediated; yet, it is still controversial to what extend implicit learning drives abstract and unconscious knowledge (Cleeremans, Destrebecqz, \& Boyer, 1998).

A crucial phase during the development of reading abilities is to learn and automatize the associations between letters and sounds. Fluent reading will benefit from the extraction of regularities from visual and auditory sequences (e.g., co-occurring letters), important for the formation of letter and word representations (Ehri, 2005). This occurs through both explicit and implicit learning processes: the former takes place throughout formal instruction and the last merely through exposure to text (Stoodley \& Stein, 2011). Hence, impaired reading in dyslexia may be related to a deficit in implicit learning. A few plausible mechanisms have been suggested to explain how a weakness in implicit learning of sequential information could account for the phonological processing and reading problems in dyslexia. The cerebellar deficit hypothesis of dyslexia (Nicolson \& Fawcett, 1999; Nicolson, Fawcett, \& Dean, 2001) claims that children with dyslexia have unusual difficulty in automatizing any skill, whether motor or cognitive. Because implicit learning has been closely linked with automatic learning mechanisms (Conway \& Pisoni, 2008), it may well be that an implicit learning deficit would affect learning of grapheme-phoneme associations in children with dyslexia and eventually prevent them from reaching a high degree of automaticity in reading (Sperling, Lu, \& Manis, 2004). Howard, Howard, Japikse, and Eden (2006) also suggest that poor implicit learning could hinder the establishment of adequate phonological processing, as well as learning orthographic-phonological representations. The authors propose that a combination of a phonological deficit with an impaired sequence learning system could manifest as a failure in applying implicit or probabilistic rules required for fluent application of grapheme-phoneme correspondences and, therefore, leading to reading difficulties (see also Sperling et al., 2004).

The capacity of implicit learning of dyslexics has been tested in a number of studies, however with contradictory results. Some studies have found that dyslexic readers have an implicit learning deficit, especially when the task has a strong sequencing component (Kahta \& Schiff, 2016; Menghini, Hagberg, Caltagirone, Petrosini, \& Vicari, 2006; Stoodley, 
Harrison, \& Stein, 2006; Vicari, Marotta, Menghini, Molinari, \& Petrosini, 2003), and a correlation between implicit learning and individuals' reading ability as been reported (Sperling et al., 2004). Other studies, however, have found null results, i.e., implicit learning abilities were apparently intact both in children and adults with dyslexia when compared to typical readers (e.g., Kelly, Griffiths, \& Frith, 2002; Nigro, Jiménez-Fernández, Simpson, \& Defior, 2016; Roodenrys \& Dunn, 2008). Furthermore, Waber et al. (2003) have found no evidence that reading ability is associated with implicit sequential learning.

Factors that varied between studies may explain the apparent discrepancies, including the tasks used to assess implicit learning (Howard et al., 2006; Roodenrys \& Dunn, 2008). For example, studies that employed two different implicit learning tasks (Howard et al., 2006; Jiménez-Fernández, Vaquero, Jiménez, \& Defior, 2010) found evidence for a deficit on the serial reaction time tasks in dyslexics compared with typical readers, while there were no differences between these groups on other implicit learning tasks, such as the spatial context learning task. Additionally, when we look in to the studies with dyslexics that employed another implicit learning task, the artificial grammar learning paradigm, we also find contradictory results (Laasonen et al., 2014; Pavlidou, Kelly, \& Williams, 2010; Pavlidou, Williams, \& Kelly, 2009; Pothos \& Kirk, 2004; Rüsseler, Gerth, \& Münte, 2006). Artificial grammar learning (AGL) tasks differ from the SRT tasks in the sense that they require less involvement of the motor system and represent a more complex and abstract implicit learning situation. Consequently, both tasks are thought to reflect different cognitive and neural processes (Laasonen et al., 2014). However, a closer look into these discrepant results presented by studies with dyslexics using the AGL task will show an important difference between them: the participants' age. While some studies with dyslexic children reported poor performance in implicit learning (Pavlidou et al., 2010; Pavlidou et al., 2009), others show that dyslexic adults even outer perform the typical readers (Pothos \& Kirk, 2004). Rüsseler et al. (2006) studied the implicit learning abilities of dyslexic adults using both AGL and SRT paradigms and observed that these individuals were unimpaired in both tasks. Laasonen et al. (2014), in turn, found no major differences between dyslexic adults and typical readers in the SRT task, only in the AGL task. In this study, there was a non-significant main effect of group, but while in control readers the grammaticality accuracy was above chance levels, in the dyslexic readers performance did not exceeded the chance level. The authors suggested that these findings could be explained by the shorter presentation time and the reduced number of items used in the learning phase that might have hampered dyslexics' performance. Overall, studies using the AGL paradigm with dyslexic children report poor implicit learning, but this deficit is probably mitigated in dyslexic adult samples. Nevertheless, it is not clear whether the poorer results presented by dyslexic children are due to participants' characteristics beyond age or to the AGL task characteristics, such as short exposure periods.

In sum, there is considerable debate on whether implicit learning is affected and contributes to impaired reading in dyslexia. In the present study, we aim to further investigate the implicit sequence learning abilities in dyslexic children, using an AGL task that was designed to minimize factors that might prevent implicit learning from occurring (such as slower performance) and, importantly, to maximize the exposure to the sequence regularities. For this, we used an extended acquisition phase ( 3 days), unlike prior studies. This is important because consolidation promoted by sleep fosters optimal performance in implicit learning (Nieuwenhuis, Folia, Forkstam, Jensen, \& Petersson, 2013). Another novelty of this study is that we compared the performance of dyslexic children with that of a control group matched for chronological age and a control group matched by reading level. The lack of such a 
reading-matched control group is an important gap in the previous studies, as its inclusion allows us to exclude that a given deficit is simply a consequence of the less reading experience in dyslexic children. If dyslexic children do have an implicit learning deficit, one would expect them to perform more poorly on the AGL task even when compared with the reading-matched controls, indicating therefore a disrupted implicit learning ability in this population.

\section{Methods and materials}

\section{Participants}

All participants were children recruited from Portuguese elementary schools (2nd-4th grade), with normal or corrected to normal vision. Informed consent was obtained from their parents. Twenty children (12 male and 8 female, mean age $\pm \mathrm{SD}=9.5 \pm 1.1$ years; mean grade $\pm \mathrm{SD}=3.1 \pm 0.9$ ) with either a formal dyslexia diagnosis or a suspicion of dyslexia (as indicated by their teachers) were further assessed in order to confirm if they met all the inclusion criteria. The inclusion criteria for the dyslexia group were (1) absence of neurological or emotional problems (including ADHD); (2) normal range non-verbal IQ as measured by the Raven Colored Matrices (Raven, Raven, \& Court, 2009); (3) reading abilities significantly below grade mean level in the reading and spelling subtests (i.e., either a reading speed score $\geq 1.25 \mathrm{SD}$ below the grade mean or a reading speed score $\geq 0.75$ SD below the grade mean combined with a spellings score $\geq 1.25$ SD below the grade mean) of the Differential Diagnosis Dyslexia battery of Maastricht-3DM (Blomert \& Vaessen, 2009; Pacheco et al., 2014); and (4) reading scores below the 25 th percentile on a reading comprehension test (Teste de Idade de Leitura-TIL; Santos \& Castro, 2010).

Two control groups were selected to match the dyslexic group: one group matched for age (age-matched control) and other matched for reading skills (reading-matched control). For the age-matched control group, 20 children (12 male and 8 female, mean age $\pm \mathrm{SD}=9.1 \pm$ 0.6 years; mean grade $\pm \mathrm{SD}=3.5 \pm 0.8$ ) classified by their teachers as average pupils were selected. For the reading-matched control group, 20 children (12 male and 8 female, mean age $\pm \mathrm{SD}=7.1 \pm 0.4$ years; mean grade $\pm \mathrm{SD}=1.4 \pm 0.5$ ) were selected from the same schools as the other children. At the time of testing, these children were at the end of the first grade or beginning of second grade and were already able to read (they were all classified by their teachers as average or above average pupils). Specific inclusion criteria for the control groups were (1) absence of neurological or emotional problems (including ADHD); (2) normal range non-verbal IQ as measured by the Raven Colored Matrices; (3) reading abilities within or above the grade mean level in the 3DM reading and spelling tests; and (4) reading scores above the 25th percentile in TIL.

A $t$ test for independent samples confirmed that the reading and spelling scores of the dyslexic group were significantly lower compared with those of the age-matched control group (both $p$ 's $<$ $0.01)$, but not compared with the reading-matched control group $(p=0.26$, for reading and $p=$ 0.08 , for spelling). The dyslexic and the age-matched control group did not differ from each other in terms of age and years of education ( $p=0.24$ and $p=0.30$, respectively), and both groups were significantly older and from a higher grade than the reading-matched control group (both $p$ 's $<$ 0.01). Additionally, all groups were initially tested on phonological awareness, rapid automatized naming [subtests selected from the 3DM battery (Pacheco et al., 2014)], vocabulary, and phonological short-term memory [from the Wechsler Intelligence Scale for Children (Wechsler, 2006)]. The dyslexic group showed significantly lower scores compared with both control groups 
in all tasks (Table 1). No differences emerged between the two control groups when raw values were converted into standardized values (all $p$ 's $\geq 0.37$ ).

\section{Stimulus material}

Using a regular grammar defined by the finite-state generator described in Fig. 1, we generated the complete set of grammatical (G) stimulus sequences with a length of 4 to 7 elements from a symbol alphabet with colored geometrical forms (green triangle, yellow square, red circle, blue diamond; see Fig. 1). The colored geometrical forms were used instead of orthographic material in order to facilitate acquisition by all children and to not benefit those without dyslexia. The stimulus material includes one acquisition set and one classification set. In order to quantify differences in subsequence familiarity between acquisition and classification items, associative chunk strength (ACS) was calculated for each sequence. The ACS captures the frequency distribution of 2- and 3-letters chunks for the complete sequence positions (Knowlton \& Squire, 1996; Meulemans \& Van Der Linden, 1997). Of the total set of grammatical sequences, 36 items were selected for the acquisition set using an iterative random procedure. This procedure guaranteed that the acquisition set was comparable in terms of ACS familiarity to the complete set. Non-grammatical (NG) items were generated by switching two geometrical forms in non-terminal positions from each remaining grammatical items, keeping the ACS score balanced with its original template item (see Appendix 1Table 2). For the classification set, 20 grammatical and 20 non-grammatical pairs were selected from the remaining items in an iterative random procedure, while ensuring that 10 items were equivalent in ACS to the acquisition set and the remaining 10 items showed a significantly lower ACS score. In this way, the classification set was organized in a $2 \times 2$ factorial design, with grammaticality (grammatical/non-grammatical) and ACS (high/low) as factors, including 10 sequences of each category: high ACS grammatical (HG), low ACS grammatical (LG), high ACS non-grammatical (HNG), and low ACS non-grammatical (LNG).

\section{Procedure}

All sessions were conducted in the schools of the children, in a quiet and undisturbed room. First, reading and cognitive assessment was performed in order to select our participants. Afterwards, participants performed the AGL experiment, divided in three sessions conducted over three consecutive days. All tasks were presented visually on a computer screen and responses were

Table 1 Group performance on the reading, spelling, phonological awareness, rapid automatized naming, vocabulary, and phonological short-term memory tasks (mean $\pm \mathrm{SD}$ ). Raw scores were used in all tasks (note that the reading-matched control group performance is adequate for their age when values are converted to standardized scores)

\begin{tabular}{lccc}
\hline & $\begin{array}{l}\text { Dyslexic group } \\
(n=20)\end{array}$ & $\begin{array}{l}\text { Age-matched control } \\
\text { group }(n=20)\end{array}$ & $\begin{array}{l}\text { Reading-matched control } \\
\text { group }(n=20)\end{array}$ \\
\hline Word reading (word/s) & $0.35 \pm 0.18$ & $1.27 \pm 0.29^{*}$ & $0.45 \pm 0.13$ \\
Spelling (\%) & $65.16 \pm 12.89$ & $85.86 \pm 6.00^{*}$ & $72.39 \pm 11.27$ \\
Phoneme deletion (\%) & $33.04 \pm 21.20$ & $79.96 \pm 13.74^{*}$ & $49.89 \pm 27.74^{*}$ \\
Rapid naming (item/s) & $1.14 \pm 0.22$ & $1.76 \pm 0.24^{*}$ & $1.27 \pm 0.19$ \\
Vocabulary (score) & $16.00 \pm 3.93$ & $19.75 \pm 5.06^{*}$ & $14.15 \pm 2.74$ \\
Digit span (score) & $8.00 \pm 1.81$ & $10.80 \pm 1.80^{*}$ & $9.10 \pm 1.94$ \\
\hline
\end{tabular}

*Mean scores significantly different from dyslexic group mean scores $(p$ 's $<0.05)$ 


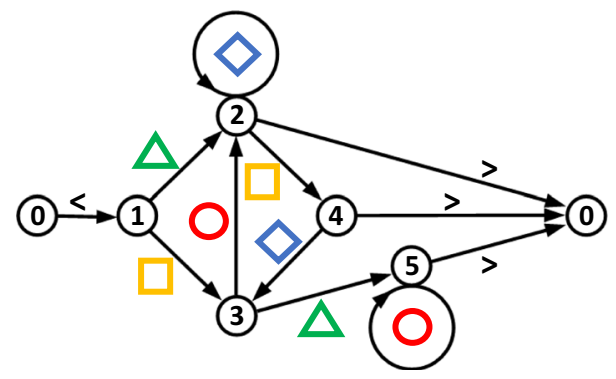

Fig. 1 The transition graph representation of the regular grammar used in the present study. Sequences that follow the transitions in this graph are grammatical while sequences that do not are not. An example of a grammatical sequence would be "square-circle-square-diamond-triangle" and a non-grammatical sequence would be "square-circle-diamond-circle-square"

recorded using a Cedrus $R B$ series response pad, connected to the laptop. All sessions started with a short-term memory cover task, the acquisition task. During this task, participants were exposed to and had to memorize grammatical sequences, which remained on the screen for $8 \mathrm{~s}$ each. After that, participants were asked to reproduce the sequence, in a self-paced manner, using the response pad to type the colored geometrical forms (one button per geometrical form). The sequences presentation order was randomized for each acquisition session and each session lasted for approximately $20 \mathrm{~min}$. After the acquisition task, participants were interviewed in order to assess the level of experienced difficulties in fulfilling this task.

On the third day, after the short-term memory task, participants engaged in an intermediate irrelevant task, in order to divert attention from the acquisition task. In this task, subjects had to press one of four buttons whenever they saw a frog in one of four matching positions of the computer screen. Subsequently, the participants' knowledge about the underlying grammatical structure was tested using a grammaticality classification test. The participants were informed about the existence of a complex set of rules that underlies the acquisition sequences structure and were instructed to classify new sequences (20 grammatical and 20 non-grammatical) in sequences that followed those rules and sequences that did not comply with those rules (i.e., grammatical or non-grammatical). Each sequence was presented on the screen for $3 \mathrm{~s}$ followed by a grammaticality judgment (forced yes/no choice). The participants were instructed to base their decision on their immediate intuition and to avoid any attempt to explicitly analyze the sequences. The presentation order was randomized and the classification test lasted for approximately $10 \mathrm{~min}$. The session finished with an interview in order to assess their explicit knowledge about any pattern or rule system.

\section{Results}

\section{Acquisition task}

The accuracy in the acquisition task was analyzed with a repeated-measure ANOVA, with the group as between-subject factor (dyslexics/age-matched controls/reading-matched controls) and the acquisition days as within-subject factor (day 1/day 2/day 3). The results showed a large main effect of group $\left[F(2,57)=14.78, p<0.001\right.$; partial $\left.\eta^{2}=0.34\right]$. A post-hoc analysis (Tukey HSD) revealed that age-matched controls performed more accurately (percentage mean $\pm \mathrm{SD}=57.46 \pm$ 7.20) than the dyslexic (percentage mean $\pm \mathrm{SD}=40.69 \pm 4.19$; Cohen's $d=2.85$ ) and readingmatched control groups (percentage mean $\pm \mathrm{SD}=36.88 \pm 5.15$; Cohen's $d=3.29$ ) (all $p$ 's $<$ 
0.001). The performance of the dyslexics and reading-matched controls did not significantly differ from each other $(p=0.61$; Cohen's $d=0.81)$. A large main effect of acquisition day was also observed $\left[F(2,114)=55.12, p<0.001\right.$; partial $\left.\eta^{2}=0.49\right]$, revealing an increase in performance over the 3 days (all $p$ 's $<0.001$ ). There was no significant interaction between the factors acquisition day and group $\left[F(4,114)=1.98, p=0.10\right.$; partial $\left.\eta^{2}=0.07\right]$.

\section{Classification performance: endorsement rates}

The classification performance was analyzed in terms of endorsement rate (i.e., an item classified as grammatical independent of the real grammaticality status of the sequence, cf. Meulemans \& Van Der Linden, 1997). Both grammaticality and ACS status influenced the endorsement rate (Figs. 2 and 3). A repeated-measures ANOVA with grammaticality (G/NG) and ACS (high- $-\mathrm{H} /$ low - L) as within-subject factors and group as a between-subject factor (dyslexics/age-matched controls/reading-matched controls) showed a large main effect of grammaticality $\left[F(1,57)=23.74, p<0.001\right.$; partial $\left.\eta^{2}=0.29\right]$, because the endorsement rate was higher for grammatical than for non-grammatical sequences (percentage mean $\pm \mathrm{SD}=$ $52.88 \pm 2.10$ and $39.36 \pm 2.50$, respectively), and a main effect of $\operatorname{ACS}[F(1,57)=50.93$, $p<0.001$; partial $\eta^{2}=0.47$, because the endorsement rate was higher for high compared to low ACS sequences (percentage mean $\pm \mathrm{SD}=53.53 \pm 2.08$ and $38.71 \pm 2.15$, respectively). The interaction between grammaticality and $\operatorname{ACS}\left[F(1,57)=18.00, p<0.001\right.$; partial $\eta^{2}=$ 0.24] was also significant. A post-hoc analysis revealed that there is an ACS effect only in the grammatical sequences: endorsement rates were significantly superior for high ACS grammatical sequences (percentage mean $\pm \mathrm{SD}=64.33 \pm 18.61$ ) versus low ACS grammatical sequences (percentage mean $\pm \mathrm{SD}=41.43 \pm 19.75 ; p<0.001$ ). Although the performance on high ACS non-grammatical sequences (percentage mean $\pm \mathrm{SD}=42.72 \pm 24.22$ ) was higher than that on low ACS non-grammatical sequences (percentage mean $\pm \mathrm{SD}=36.00 \pm 19.76$ ), this difference was only near significance $(p=0.07)$.

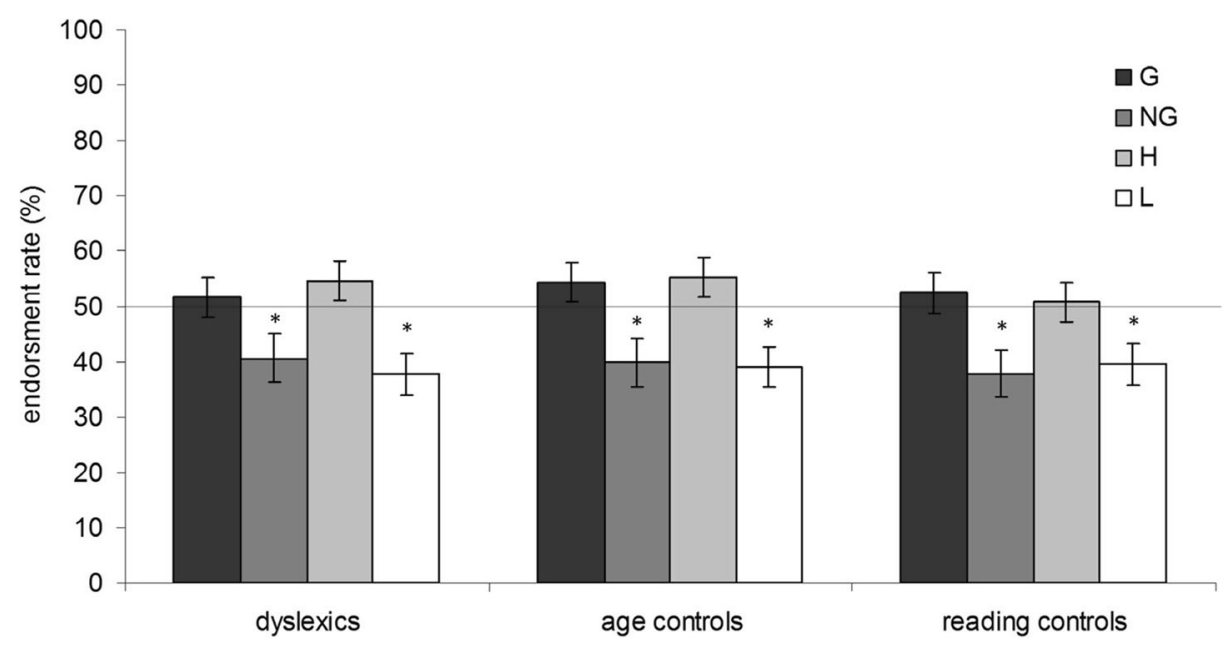

Fig. 2 Endorsement rates over grammaticality and ACS as main factor categories. (G: grammatical sequences; NG: non-grammatical sequences; H: high ACS sequences; L: low ACS sequences). Error bars correspond to standard error of the mean. A single asterisk $(*)$ indicates that average endorsement rate is significantly different from chance $(t$ test, $p<0.05)$ 


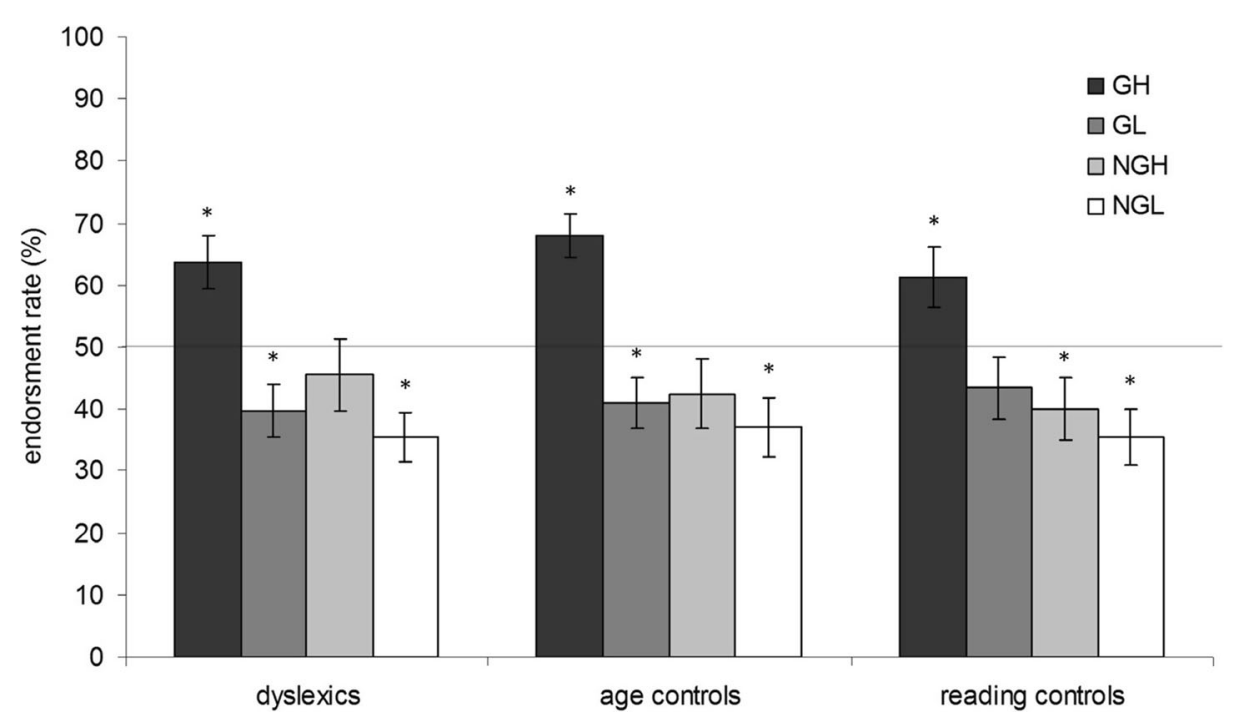

Fig. 3 Endorsement rates over grammaticality and ACS levels (GH: grammatical high ACS sequences; GL: grammatical low ACS sequences; NGH: non-grammatical high ACS sequences; NGL: non-grammatical low ACS sequences). Error bars correspond to standard error of the mean. A single asterisk (*) indicates that average endorsement rate is significantly different from chance $(t$ test, $p<0.05)$

Importantly, there was no main effect of group $\left[F(2,57)=0.10, p=0.903\right.$; partial $\eta^{2}=$ 0.004]. Furthermore, neither the effect of grammaticality nor of ACS interacted with the factor group, as indicated by the non-significant two-way interactions (group by grammaticality: $F$ $(2,57)=0.18, p=.83$; partial $\eta^{2}=0.01$; group by ACS: $F(2,57)=0.78, p=0.46$; partial $\eta^{2}=$ 0.03 ) and the non-significant three-way interaction $\left[F(2,57)=0.49, p=0.62\right.$, partial $\eta^{2}=$ $0.017]$.

In addition to the endorsement rate analysis, we performed further a response time analysis as, despite unimpaired accuracy performance, dyslexics showed slower response times, which could reflect different cognitive processes when dealing with the task (see, for example, Kelly et al., 2002). However, we find no significant differences between groups or conditions in the response times (all $p$ 's $\geq 0.08$ ).

\section{Individual analysis}

While we found no differences between groups on the classification task performance, it may be that by performing a group level analysis we have missed relevant individual aspects. Thus, we further used an individual-level approach to investigate performance on the AGL task (Fig. 4). In this analysis, four dyslexic children performed high above the chance level, indicating that these participants were able to discriminate between grammatical and non-grammatical items. Four participants in the age-matched control group and seven participants in the reading-matched control group were also very good on the classification task, as shown by their $d$ ' values. Some children presented very high levels of discrimination in the opposite direction (expressed by their strong negative $d$ ' values), probably because of misinterpretation of the instructions or confusion with the response buttons. We re-analyzed the data excluding these participants and no changes were observed in the overall pattern of results. 


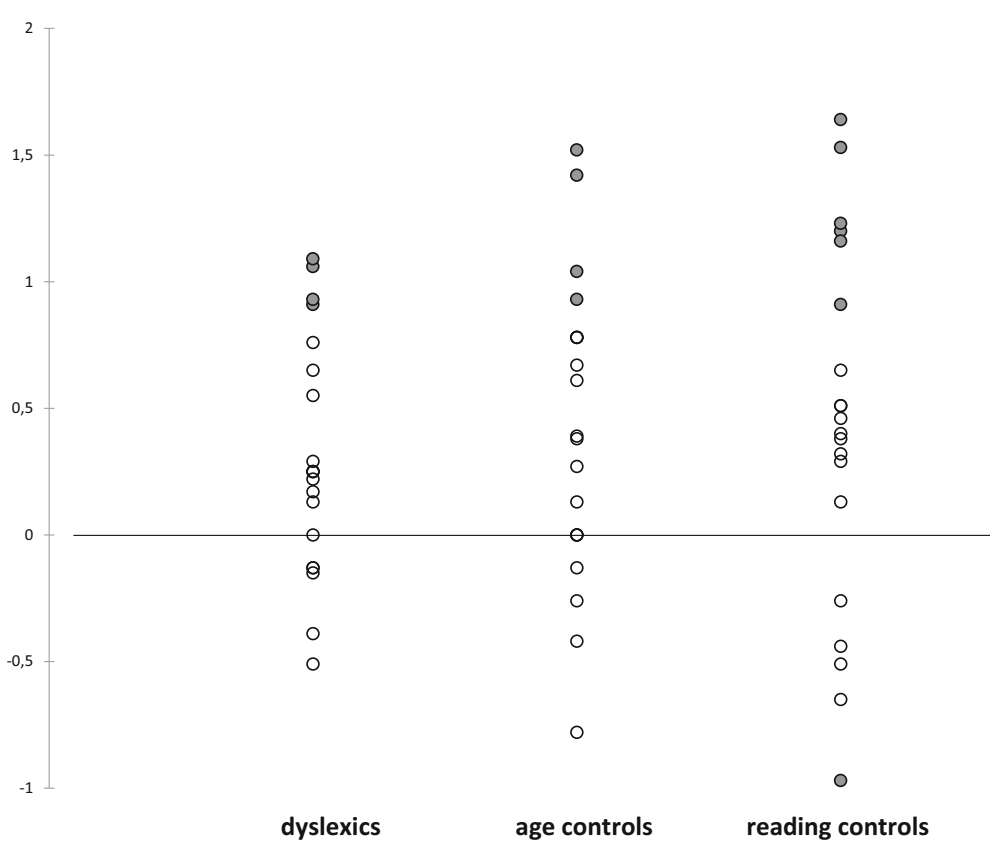

Fig. $4 d$ ' for grammaticality by participant (age controls = age-matched control group; reading controls = reading-matched control group; filled dots for accuracy level above chance (binomial test $p<0.05$, two-tailed))

\section{Explicit knowledge}

In order to assess if participants were using or were aware of any rule system underlying the sequences, they were interviewed at the end of the acquisition and classification tasks. After the classification task, the participants were asked to reproduce grammatical sequences using cards with the colored geometrical forms that they had been previously presented. Participants were aware of a few salient characteristics (namely, all sequences started with triangles or squares and these shapes, contrary to others, were never repeated in a sequence). These salient features were uncovered in the acquisition task for some children; others only reported them after the classification task. Some of the children were able to create grammatical sequences with the cards (maximum of five correct sequences), all corresponding to sequences that they saw in the acquisition task. This ability to generate grammatical sequences did not correlate with the grammatical discrimination index, $d^{\prime}(r=$ $0.11, p=0.39$ ). Therefore, there is evidence of explicit knowledge for the sequences presented in the acquisition task, but there is no evidence of such knowledge for the grammatical rules, since the children could not produce new grammatical sequences or made explicit rules that are more complex. Furthermore, the fragmented explicit knowledge the participants have (i.e., which geometrical forms can be repeated and those used to start the sequences) does not benefit them since all sequences in the classification task — both grammatical and non-grammatical— display those features.

\section{Discussion}

This study aimed to investigate whether dyslexic children can accomplish implicit sequence acquisition in an artificial grammar learning paradigm. In the classification task, new 
grammatical and non-grammatical sequences were presented and participants were asked to classify them. In this test, there were no differences between dyslexic and any of the control groups (age- and reading-matched control), indicating that regardless of their reading status all participants acquired the stimulus regularities at a similar level. The endorsement rates were also influenced by grammaticality likewise: all participants rejected non-grammatical sequences and there was a leaning to accept grammatical sequences.

Regarding the acquisition task, we did observe an effect of group as the age-matched control group performed better than both the dyslexic and the reading-matched control groups (which in turn did not differ from each other). This result is somehow expected as dyslexic children have been shown to present poor short-term memory (e.g., Trecy, Steve, \& Martine, 2013; or Wang \& Gathercole, 2013), and the acquisition task relies strongly on this skill. In reading-matched controls, we do not believe this is the case; their lower performance probably reflects their development stage (Gathercole, Pickering, Ambridge, \& Wearing, 2004). Nevertheless, the performance in this task did not mirror the performance in the classification task. It has been already shown that implicit learning is not related with working memory (Kaufman et al., 2010). Furthermore, a poorer working memory capacity (as dyslexics in our group present - see Table 1) did not prevent them from extracting the regularities of the sequences presented in the acquisition task. In line with these results, Conway, Bauernschmidt, Huang, and Pisoni (2010) suggested that even if the ability to encode and hold a series of items in immediate memory is necessary to learn a sequence structure, this ability per se is not sufficient, and a well-functioning mechanism involved in learning the underlying regularities is also needed. Consequently, a reduced memory capacity might actually be beneficial for learning complex input because it can act as a filter to reduce the complexity of the problem space, making it more manageable. The participants' working memory capacity could aid the sequence learning in both directions but through different mechanisms: for the controls, a better working memory helps them to encode and hold the sequence items more efficiently, improving the sequence structure learning. For the dyslexics, a poorer working memory capacity may force them to transform the sequence items into more manageable units that would support the capture of the sequence structure.

For all tested groups, the performance in the classification task was below what was expected. Most of our participants, either dyslexic or typical readers, performed at chance level. Specifically, and as Siegelman and collaborators noted (see Siegelman, Bogaerts, Christiansen, \& Frost, 2017a; Siegelman, Bogaerts, \& Frost, 2017b), this may have occurred because of the reduced number of trials or the homogeneous level of difficulty across trials in the classification task. The effect sizes observed in the group analysis and the individual participants' performance showed that at least some of the dyslexic children did reach high levels of grammaticality discrimination, like typical readers do. Additionally, the post-experimental interviews and sequence generation task results confirmed that no group in our study acquired explicit knowledge of the underlying grammatical system. Therefore, the overall pattern of results seems to indicate that implicit learning of the artificial grammar is preserved in dyslexic children.

Our results diverge from those obtained by Pavlidou and colleagues, who also tested dyslexic children using an AGL task with similar set of stimuli, but with a different paradigm (Pavlidou et al., 2010, 2009). Their results showed that while dyslexic children were performing at chance levels, the typically developing children were able to successfully distinguish between grammatical and non-grammatical items. From these results, the authors suggested that dyslexic children were not as able as typical readers in abstracting implicit knowledge, that is, to extract the regularities of highly complex 
structured patterns such as AGL (Pavlidou et al., 2010). However, we might argue that in Pavlidou's studies, the acquisition process employed did not allow the dyslexic children to extract and/or consolidate the regularities of the sequences. It has already been shown that dyslexic individuals may need different strategies to cope with implicit learning tasks. For example, Kelly et al. (2002) and Roodenerys and Dunn (2008) showed that although dyslexics performed at the same level as typical readers in a SRT task, they were slower. In the studies performed by Pavlidou et al. (2010, 2009), there was a limited exposure to grammatical items (only one acquisition session followed by an immediate classification test) that might led to a poor consolidation (Nieuwenhuis et al., 2013), probably hampering dyslexics' performance. To our knowledge, the present study was the first to extend the acquisition phase to 3 days with an AGL task in children with dyslexia. We did not measure the classification performance in the first 2 days, but still we consider that overnight consolidation processes and extended practice might have enhanced participants' performance for all groups (but see also Hedenius et al., 2013). A longer period of practice and exposure to grammatical sequences would perhaps even increase their classification performance and eliminate the ACS effect observed: the regularity extraction might have been placed into the smaller units due to still weak consolidation processes. On the other hand, the ACS effect might have been enhanced by the instruction given in the acquisition task (memorize and reproduce the grammatical sequences), which emphasizes lower (constituent element) and mid-level knowledge (bigrams) (cf. Pavlidou, 2010). Future studies favoring the consolidation processes with a less demanding load on item memorization might help to unravel if the observation of an impaired performance by dyslexic children in previous AGL studies (Pavlidou et al., 2010, Pavlidou et al., 2009) is due to insufficient exposure to grammatical regularities, and if the ACS effect is due to task demands.

Finally, another aspect that deserves consideration is the focus on group level analysis in prior studies of implicit learning in dyslexia. This kind of analysis may conceal positive individual achievements and one wonder whether there were in these studies at least some dyslexic individuals who have their implicit learning abilities intact. In fact, in the present study and consonant with Stoodley et al. (2006), in the individual-level analysis, we observed that some dyslexics present a high level of discrimination between grammatical and nongrammatical sequences. This finding might reflect the substantial heterogeneity of deficits found in dyslexia (Stoodley et al., 2006). It is also possible that the divergent results in the literature reflect both the variation of tasks used (see, for example, Howard et al., 2006; Jiménez-Fernández et al., 2010; Rüsseler et al., 2006) but also sample characteristics, as studies typically differ in their operational definitions of dyslexia (e.g., cut-off levels for reading and IQ). In our study, we tried to disentangle if those dyslexic children who presented a high performance in the AGL classification had different cognitive characteristics from those who had a worse performance, but we did not find any consistent pattern; therefore, we cannot draw any conclusion on this issue. Future studies using a larger sample of dyslexics, a more detailed assessment of their deficits and including an individual-level analysis could clarify this question.

In conclusion, the present study showed that dyslexic children are able to extract the implicit regularities of an artificial grammar to a similar degree as typical readers do, at least as long as sufficient consolidation is allowed. Remediation programs are encouraged to exploit this implicit learning ability, through the promotion of ludic pedagogical activities in which children are incidentally exposed to linguistic regularities (such as orthographic patterns) 
outside reading and writing tasks. Further research is needed to evaluate the impact of such pedagogical interventions based on implicit learning strategies for dyslexia remediation.

Funding information This work was supported by national Portuguese funding through Fundação para a Ciência e a Tecnologia, project ref. UID/BIM/04773/2013 CBMR, PTDC/MHC-PCN/1175/2014, and SFRH/BD/85439/2012.

\section{Appendix}

Table 2 Stimulus material. Mean ACS (standard deviations in parenthesis and range in brackets) and length distribution for sequences used in acquisition and classification tasks

\begin{tabular}{|c|c|c|c|c|c|c|}
\hline & \multirow[t]{2}{*}{$n$} & \multirow[t]{2}{*}{ Mean ACS } & \multicolumn{4}{|c|}{$\%$ of stimulus type per sequence length } \\
\hline & & & 4 letters & 5 letters & 6 letters & 7 letters \\
\hline Acquisition set & 36 & $15.73(1.49)[10.40-18.33]$ & 13.9 & 22.2 & 25.0 & 38.9 \\
\hline \multicolumn{7}{|l|}{ Classification set } \\
\hline $\mathrm{GH}$ & 10 & $15.61(1.75)$ [12.64-17.45] & 0 & 10 & 30 & 60 \\
\hline GL & 10 & $8.37(2.46)[4.73-12.09]$ & 0 & 20 & 30 & 50 \\
\hline $\mathrm{NGH}$ & 10 & 15.45 (1.87) [12.36-17.64] & 0 & 10 & 30 & 60 \\
\hline NGL & 10 & $8.11(2.44)[4.45-12.00]$ & 0 & 20 & 30 & 50 \\
\hline
\end{tabular}

$A C S$ associative chunk strength, $G$ grammatical, $N G$ non-grammatical, $H$ high ACS, $L$ low ACS

\section{References}

Blomert, L., \& Vaessen, A. (2009). Differentiaal Diagnostiek van Dyslexie: cognitieve analyse van lezen en spellen [Dyslexia Differential Diagnosis: cognitive analysis of reading and spelling]. Amsterdam: Boom.

Boets, B., Beeck, H. O., Vandermosten, M., Scott, S. K., Gillebert, C. R., Mantini, D., et al. (2013). Intact but less accessible phonetic representations in adults with dyslexia. Science, 342(6163), 1251-1254. https://doi. org/10.1126/science. 1244333 .

Cleeremans, A., Destrebecqz, A., \& Boyer, M. (1998). Implicit learning: news from the front. Trends in Cognitive Sciences, 2(10), 406-416. https://doi.org/10.1016/S1364-6613(98)01232-7.

Conway, C. M., Bauernschmidt, A., Huang, S. S., \& Pisoni, D. B. (2010). Implicit statistical learning in language processing: word predictability is the key. Cognition, 114(3), 356-371. https://doi.org/10.1016/j. cognition.2009.10.009.

Conway, C. M., \& Pisoni, D. B. (2008). Neurocognitive basis of implicit learning of sequential structure and its relation to language processing. Annals of the New York Academy of Sciences, 1145, 113-131. https://oi. org/10.1196/annals.1416.009.

Ehri, L. C. (2005). Learning to read words: theory, findings, and issues. Scientific Studies of Reading, 9(2), 167188. https://doi.org/10.1207/s1532799xssr0902_4.

Folia, V., Uddén, J., Forkstam, C., Ingvar, M., Hagoort, P., \& Petersson, K. M. (2008). Implicit learning and dyslexia. Annals of the New York Academy of Sciences, 1145, 132-150. https://doi.org/10.1196 /annals.1416.012.

Franceschini, S., Gori, S., Ruffino, M., Pedrolli, K., \& Facoetti, A. (2012). A causal link between visual spatial attention and reading acquisition. Current Biology, 22(9), 814-819. https://doi.org/10.1016/j. cub.2012.03.013.

Gathercole, S. E., Pickering, S. J., Ambridge, B., \& Wearing, H. (2004). The structure of working memory from 4 to 15 years of age. Developmental Psychology, 40(2), 177-190. https://doi.org/10.1037/00121649.40.2.177.

Hedenius, M., Persson, J., Alm, P. A., Ullman, M. T., Howard, J. H., Howard, D. V, \& Jennische, M. (2013). Impaired implicit sequence learning in children with developmental dyslexia. Research in Developmental Disabilities, 34(11), 3924-3935. https://doi.org/10.1016/j.ridd.2013.08.014

Howard, J. H., Howard, D. V., Japikse, K. C., \& Eden, G. F. (2006). Dyslexics are impaired on implicit higherorder sequence learning, but not on implicit spatial context learning. Neuropsychologia, 44(7), 1131-1144. https://doi.org/10.1016/j.neuropsychologia.2005.10.015. 
Jiménez-Fernández, G., Vaquero, J. M. M., Jiménez, L., \& Defior, S. (2010). Dyslexic children show deficits in implicit sequence learning, but not in explicit sequence learning or contextual cueing. Annals of Dyslexia, 61(1), 85-110. https://doi.org/10.1007/s11881-010-0048-3.

Kahta, S., \& Schiff, R. (2016). Implicit learning deficits among adults with developmental dyslexia. Annals of Dyslexia, 66(2), 235-250. https://doi.org/10.1007/s11881-016-0121-7.

Kaufman, S. B., Deyoung, C. G., Gray, J. R., Jiménez, L., Brown, J., \& Mackintosh, N. (2010). Implicit learning as an ability. Cognition, 116(3), 321-340. https://doi.org/10.1016/j.cognition.2010.05.011.

Kelly, S. W., Griffiths, S., \& Frith, U. (2002). Evidence for implicit sequence learning in dyslexia. Dyslexia, 8(1), 43-52. https://doi.org/10.1002/dys.208.

Knowlton, B. J., \& Squire, L. R. (1996). Artificial grammar learning depends on implicit acquisition of both abstract and exemplar-specific information. Journal of Experimental Psychology: Learning, Memory, and Cognition, 22(1), 169-181. https://doi.org/10.1037/0278-7393.22.1.169.

Laasonen, M., Vare, J., Oksanen-Hennah, H., Leppamaki, S., Tani, P., Harno, H., et al. (2014). Project DyAdd: implicit learning in adult dyslexia and ADHD. Annals of Dyslexia, 64(1), 1-33. https://doi.org/10.1007 /s11881-013-0083-y.

Lum, J. A. G., Ullman, M. T., \& Conti-Ramsden, G. (2013). Procedural learning is impaired in dyslexia: evidence from a meta-analysis of serial reaction time studies. Research in Developmental Disabilities, 34(10), 3460-3476. https://doi.org/10.1016/j.ridd.2013.07.017.

Lyon, G. R., Shaywitz, S. E., \& Shaywitz, B. A. (2003). Defining dyslexia, comorbidity, teachers' knowledge of language and reading: a definition of dyslexia. Annals of Dyslexia, 53, 1-14. https://doi.org/10.1007/s11881003-0001-9.

Menghini, D., Hagberg, G. E., Caltagirone, C., Petrosini, L., \& Vicari, S. (2006). Implicit learning deficits in dyslexic adults: an fMRI study. NeuroImage, 33(4), 1218-1226. https://doi.org/10.1016/j. neuroimage.2006.08.024.

Meulemans, T., \& Van Der Linden, M. (1997). Associative chunk strength in artificial grammar learning. Journal of Experimental Psychology: Learning, Memory, and Cognition, 23(4), 1007-1028. https://doi.org/10.1037 /0278-7393.23.4.1007.

Nicolson, R. I., \& Fawcett, A. J. (1999). Developmental dyslexia: the role of the cerebellum. Dyslexia, 5(3), 155177. https://doi.org/10.1002/(SICI)1099-0909.

Nicolson, R. I., Fawcett, A. J., \& Dean, P. (2001). Developmental dyslexia: the cerebellar deficit hypothesis. Trends in Neurosciences, 24(9), 508-511 https://doi.org/10.1016/S0166-2236(00)01896-8.

Nieuwenhuis, I. L. C., Folia, V., Forkstam, C., Jensen, O., \& Petersson, K. M. (2013). Sleep promotes the extraction of grammatical rules. PLoS One, 8(6), e65046. https://doi.org/10.1371/journal.pone.0065046.

Nigro, L., Jiménez-Fernández, G., Simpson, I. C., \& Defior, S. (2016). Implicit learning of non-linguistic and linguistic regularities in children with dyslexia. Annals of Dyslexia, 66(2), 202-218. https://doi.org/10.1007 /s11881-015-0116-9.

Pacheco, A., Reis, A., Araújo, S., Inácio, F., Petersson, K. M., \& Faísca, L. (2014). Dyslexia heterogeneity: cognitive profiling of Portuguese children with dyslexia. Reading and Writing, 27(9), 1529-1545. https://doi.org/10.1007/s11145-014-9504-5.

Pavlidou, E. V., Kelly, M. L., \& Williams, J. M. (2010). Do children with developmental dyslexia have impairments in implicit learning? Dyslexia, 16, 143-161. https://doi.org/10.1002/dys.

Pavlidou, E. V., Williams, J. M., \& Kelly, L. M. (2009). Artificial grammar learning in primary school children with and without developmental dyslexia. Annals of Dyslexia, 59(1), 55-77. https://doi.org/10.1007/s11881009-0023-Z.

Pothos, E. M., \& Kirk, J. (2004). Investigating learning deficits associated with dyslexia. Dyslexia, 10(1), 61-76. https://doi.org/10.1002/dys.266.

Ramus, F., Rosen, S., Dakin, S. C., Day, B. L., Castellote, J. M., White, S., \& Frith, U. (2003). Theories of developmental dyslexia: insights from a multiple case study of dyslexic adults. Brain, 126(4), 841-865. https://doi.org/10.1093/brain/awg076.

Raven, J., Raven, J. C., \& Court, J. H. (2009). CPM-P Matrizes Progressivas Coloridas (Forma Paralela). Lisboa: Cegoc.

Reber, A. S. (1967). Implicit learning of artificial grammars. Journal of Verbal Learning and Verbal Behavior, 6 , 855-863. https://doi.org/10.1016/S0022-5371(67)80149-X.

Roodenrys, S., \& Dunn, N. (2008). Unimpaired implicit learning in children with developmental dyslexia. Dyslexia, 14, 1-15. https://doi.org/10.1002/dys.

Rüsseler, J., Gerth, I., \& Münte, T. F. (2006). Implicit learning is intact in adult developmental dyslexic readers: evidence from the serial reaction time task and artificial grammar learning. Journal of Clinical and Experimental Neuropsychology, 28(5), 808-827. https://doi.org/10.1080/13803390591001007.

Santos, A. S., \& Castro, S. L. (2010). Aprender a ler e avaliar a leitura. O TIL: teste de Idade de Leitura (2nd ed.). Coimbra: Almedina. 
Schmalz, X., Altoè, G., \& Mulatti, C. (2017). Statistical learning and dyslexia: a systematic review. Annals of Dyslexia, 67(2), 147-162. https://doi.org/10.1007/s11881-016-0136-0.

Sela, I. (2014). Visual and auditory synchronization deficits among dyslexic readers as compared to non-impaired readers: a cross-correlation algorithm analysis. Frontiers in Human Neuroscience, 8, 364. https://doi. org/10.3389/fnhum.2014.00364.

Shaywitz, S. (2003). Overcoming dyslexia. New York: Vintage Books.

Siegelman, N., Bogaerts, L., Christiansen, M. H., \& Frost, R. (2017a). Towards a theory of individual differences in statistical learning. Philosophical Transactions of the Royal Society B: Biological Sciences, 372(1711), 20160059. https://doi.org/10.1098/rstb.2016.0059.

Siegelman, N., Bogaerts, L., \& Frost, R. (2017b). Measuring individual differences in statistical learning: current pitfalls and possible solutions. Behavior Research Methods, 49(2), 418-432. https://doi.org/10.3758/s13428016-0719-z.

Sperling, A. J., Lu, Z.-L., \& Manis, F. R. (2004). Slower implicit categorical learning in adult poor readers. Annals of Dyslexia, 54(2), 281-303. https://doi.org/10.1007/s11881-004-0014-z.

Stoodley, C. J., Harrison, E. P. D., \& Stein, J. F. (2006). Implicit motor learning deficits in dyslexic adults. Neuropsychologia, 44(5), 795-798. https://doi.org/10.1016/j.neuropsychologia.2005.07.009.

Stoodley, C. J., \& Stein, J. F. (2011). The cerebellum and dyslexia. Cortex, 47(1), 101-116. https://doi. org/10.1016/j.cortex.2009.10.005.

Tijms, J. (2004). Verbal memory and phonological processing in dyslexia. Journal of Research in Reading, 27(3), 300-310. https://doi.org/10.1111/j.1467-9817.2004.00233.x.

Trecy, M. P., Steve, M., \& Martine, P. (2013). Impaired short-term memory for order in adults with dyslexia. Research in Developmental Disabilities, 34(7), 2211-2223. https://doi.org/10.1016/j.ridd.2013.04.005.

Tunmer, W., \& Greaney, K. (2011). Defining dyslexia. Journal of Learning Disabilities, 43(3), $229-243$. https://doi.org/10.1177/0022219409345009.

van Witteloostuijn, M., Boersma, P., Wijnen, F., \& Rispens, J. (2017). Visual artificial grammar learning in dyslexia: a meta-analysis. Research in Developmental Disabilities, 70, 126-137. https://doi.org/10.1016/j. ridd.2017.09.006

Vellutino, F. R., Fletcher, J. M., Snowling, M. J., \& Scanlon, D. M. (2004). Specific reading disability (dyslexia): what have we learned in the past four decades? Journal of Child Psychology and Psychiatry, 45(1), 2-40. https://doi.org/10.1046/j.0021-9630.2003.00305.x.

Vicari, S., Marotta, L., Menghini, D., Molinari, M., \& Petrosini, L. (2003). Implicit learning deficit in children with developmental dyslexia. Neuropsychologia, 41(1), 108-114. https://doi.org/10.1016/S0028-3932(02 )00082-9.

Waber, D. P., Marcus, D. J., Forbes, P. W., Bellinger, D. C., Weiler, M. D., Sorensen, L. G., \& Curran, T. (2003). Motor sequence learning and reading ability: is poor reading associated with sequencing deficits? Journal of Experimental Child Psychology, 84(4), 338-354. https://doi.org/10.1016/S0022-0965(03)00030-4.

Wagner, R. K., Torgesen, J. K., \& Rashotte, C. A. (1994). Development of reading-related phonological processing abilities: new evidence of bidirectional causality from a latent variable longitudinal study. Developmental Psychology, 30(1), 73-87. https://doi.org/10.1037/0012-1649.30.1.73.

Wang, S., \& Gathercole, S. E. (2013). Working memory deficits in children with reading difficulties: memory span and dual task coordination. Journal of Experimental Child Psychology, 115(1), 188-197. https://oi. org/10.1016/j.jecp.2012.11.015.

Wechsler, D. (2006). Wechsler intelligence scale for children (3rd ed.). Lisboa: Cegoc. 